\title{
Wilkie Syndrome behind Crohn Disease? Superior Mesenteric Artery Syndrome Mimicking and Complicating Crohn Disease of the Upper Gastrointestinal Tract
}

\author{
Luís Carvalho Lourenço Alexandra Martins Ana Maria Oliveira \\ David Valadas Horta Jorge Reis \\ Gastroenterology Department, Hospital Prof. Doutor Fernando Fonseca, Amadora, Portugal
}

Keywords

Crohn disease $\cdot$ Intestinal obstruction $\cdot$ Superior mesenteric artery syndrome

\section{Wilkie Ou Crohn? Síndrome da Artéria Mesentérica Superior a Imitar e a Complicar Doença de Crohn do Tubo Digestivo Alto}

\section{Palavras Chave}

Doença de Crohn · Obstrução Intestinal •

Síndrome da Artéria Mesentérica Superior

We read with great interest the recent paper by Pires et al. [1]. Superior mesenteric artery (SMA) syndrome, also known as Wilkie syndrome, can be idiopathic and, as shown in the former case, may have a genetic predisposition. However, it can also be secondary to other medical conditions and sometimes difficult to distinguish from those.

In 2013, a 36-year-old female presented to our department with epigastric pain, early satiety, and recurrent postprandial vomiting together with significant weight

\section{KARGER}

E-Mail karger@karger.com www.karger.com/pjg
(C) 2016 Sociedade Portuguesa de Gastrenterologia Published by S. Karger AG, Basel

Karger

Open access

This article is licensed under the Creative Commons AttributionNonCommercial-NoDerivatives 4.0 International License (CC BYNC-ND) (http://www.karger.com/Services/OpenAccessLicense) Usage and distribution for commercial purposes as well as any distribution of modified material requires written permission. loss (22\% in the previous 6 months; body mass index 17 ). She had a history of gastric and duodenal peptic ulcers associated with Helicobacter pylori $(\mathrm{Hp})$ infection, which led to Hp eradication in 2007.

An upper endoscopy was performed, revealing an ulcerated pyloric stenosis, 4 duodenal ulcers $(5-12 \mathrm{~mm}$ in diameter), a dilated duodenal bulb with cobblestone appearance, and a stricture in the third portion of the duodenum (D3) that could not be passed through (Fig. 1).

Gastric biopsies revealed chronic non-atrophic gastritis, and duodenal biopsies showed an intense chronic lymphoplasmacytic infiltrate of the mucosa and submucosa. No microorganisms (including $\mathrm{Hp}$ ) or granulomas were identified. Biopsies of the stricture showed mucosal edema but no significant inflammatory infiltrate.

Total colonoscopy with ileoscopy was normal. AntiSaccharomyces cerevisae antibodies (IgG-IgA) were positive (titer 1:1,000).

Given the persistence of gastroduodenal ulcers after previous optimal therapy for peptic disease as well as other endoscopic changes, chronic inflammation in the duodenal mucosa and submucosa, positive anti-S. cerevisae antibodies, and a duodenal stenosis after ruling out other relevant conditions, we established the diagnosis of Crohn disease $(\mathrm{CD})$ involving the upper gastrointestinal tract. 
Fig. 1. Endoscopic images from upper endoscopy. Ulcerated pyloric stenosis (a), duodenal ulcer (b), duodenal mucosa with pseudopolypoid and cobblestone-like appearance (c), and a tight stricture in the third portion of the duodenum (d).

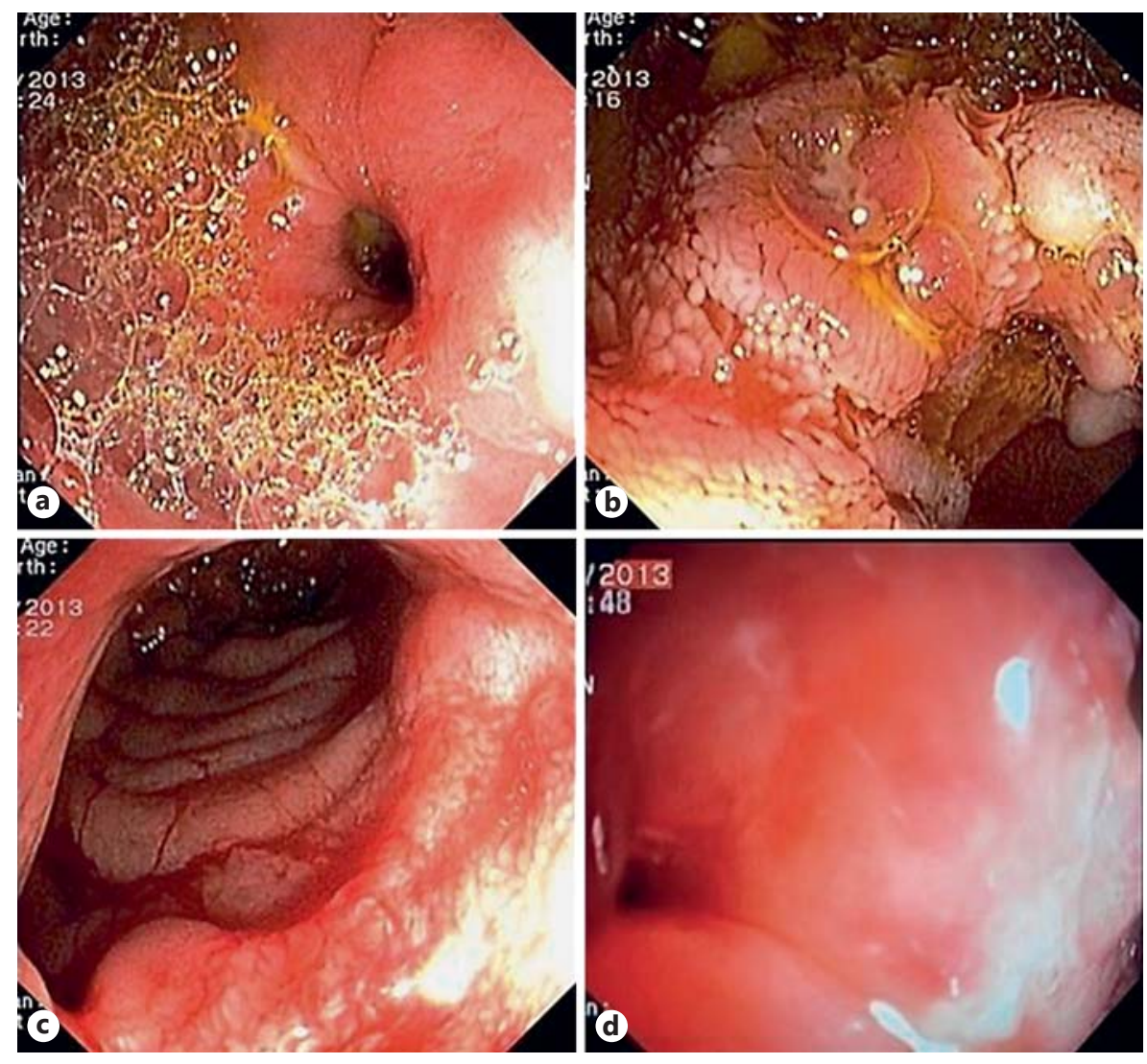

Magnetic resonance enterography revealed thickening of the antrum and proximal duodenum with inflammatory aspects. Furthermore, gastric and proximal duodenal dilation could be seen before an abrupt narrowing of the lumen in D3 (aortal-mesenteric cross) where it was possible to identify a reduced angle between the aorta and the SMA $\left(10^{\circ}\right)$ with drastic reduction of the distance between them (6-8 mm) (Fig. 2).

These findings were judged as a superimposed Wilkie syndrome in a patient with gastroduodenal CD following a period of severe weight loss.

Therapy with double-dose proton pump inhibitor, prokinetics, and a course of systemic steroids was started with rapid clinical improvement.

The patient was discharged 2 weeks later being able to tolerate oral intake. Immunomodulator therapy with azathioprine was started (with dose optimization till $2.5 \mathrm{mg}$ / $\mathrm{kg}$ ) while tapering steroids for maintenance of remission.

The patient progressively gained weight and remained in clinical and endoscopic remission during follow-up.

SMA/Wilkie syndrome can be defined as trapping of D3 between the SMA and the aorta secondary to bowel

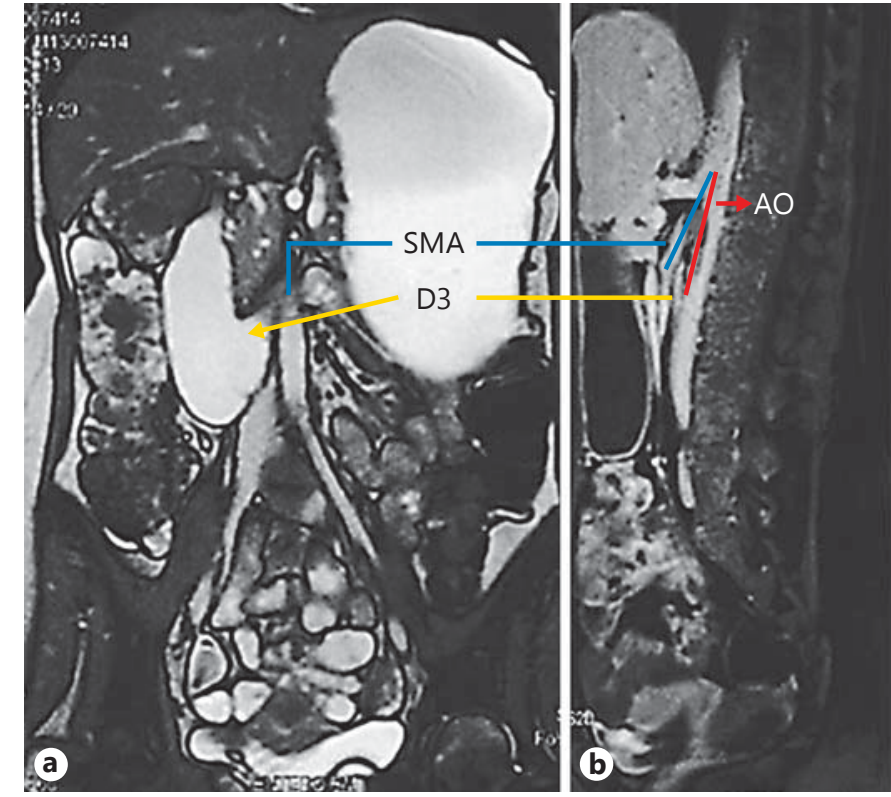

Fig. 2. Magnetic resonance enterography showing compression of the duodenum between the aorta and the SMA. Coronal (a) and sagital (b) views. SMA, superior mesenteric artery; AO, aorta; D3, third portion of the duodenum. 
compression between the 2 vessels. It may be related to a rapid decrease in the fat mesenteric tissue due to several medical conditions such as CD, alimentary disorders, or after surgery [2]. It is a rare condition (prevalence of $0.013-0.3 \%$ ) [3], more frequently found in females and young adults.

Oral contrast imaging methods are useful for diagnosis. Typically, there is dilation before the aortomesenteric cross (D3), narrowing of the aorta-SMA angle $<25^{\circ}$, and the aortomesenteric distance decreases to $<10 \mathrm{~mm}$ (normal range 10-28) [4]. Treatment can be conservative, with the aim of regaining normal body weight and resolving secondary causes (if present), or surgical, when other approaches fail $[2,4]$.

Wilkie syndrome has been reported in association with CD before [5] and in the postoperative setting of inflammatory bowel diseases [6]. To our knowledge, it has not been previously reported as "hiding" behind CD of the upper gastrointestinal tract. Diagnosis of SMA syndrome can be difficult per se. When it presents in relation to other medical conditions, an even higher degree of suspicion is necessary.

References

1 Pires S, Veloso N, Dinis-Silva J: A rare cause of proximal intestinal obstruction. GE Port J Gastroenterol 2016;23:175-176.

2 Mandarry MT, Zhao L, Zhang C, Wei ZQ: A comprehensive review of superior mesenteric artery syndrome. Eur Surg 2010;42:229-236.

3 Welsch T, Buchler MW, Kienle P: Recalling superior mesenteric artery syndrome. Dig Surg 2007;24:149-156.

4 Merrett ND, Wilson RB, Cosman P, Biankin $\mathrm{AV}$ : Superior mesenteric artery syndrome: diagnosis and treatment strategies. J Gastrointest Surg 2009;13:287-292.
5 Salam HA: Superior mesenteric artery syndrome. http://www.radiopaedia.org/cases/superior-mesenteric-artery-syndrome- 2 (accessed June 10, 2016).

6 Ballantyne GH, Graham SM, Hammers L, Modlin IM: Superior mesenteric artery syndrome following ileal J-pouch anal anastomosis. An iatrogenic cause of early postoperative obstruction. Dis Colon Rectum 1987;30:472474 